Boise State University

ScholarWorks

Psychological Sciences Faculty Publications and

Presentations

$11-1-2011$

Associations Between Young Adults' Use of Sexually Explicit Materials and Their Sexual Preferences, Behaviors, and Satisfaction

Elizabeth M. Morgan

Boise State University 


\title{
Associations Between Young Adults' Use of Sexually Explicit Materials and Their Sexual Preferences, Behaviors, and Satisfaction
}

\author{
Elizabeth M. Morgan \\ Boise State University
}

\begin{abstract}
The present study examined how levels of sexually explicit material (SEM) use during adolescence and young adulthood were associated with sexual preferences, sexual behaviors, and sexual and relationship satisfaction. Participants included 782 heterosexual college students (326 men and $456 \mathrm{w}$ omen; $M_{\text {age }}=19.9$ ) who completed a questionnaire online. Results revealed high frequencies and multiple types and contexts of SEM use, with men's usage rates systematically higher than women's. Regression analyses revealed that both the frequency of SEM use and number of SEM types viewed were uniquely associated with more sexual experience (a higher number of overall and casual sexual intercourse partners as well as a lower age at first intercourse). Higher frequencies of SEM use were associated with less sexual and relationship satisfaction. The frequency of SEM use and number of SEM types viewed were both associated with higher sexual preferences for the types of sexual practices typically presented in SEM. These findings suggest that SEM use can play a significant role in a variety of aspects of young adults' sexual development processes.
\end{abstract}

Keywords: pornography, sexual development, media, sexual attitudes

Young adulthood is a time a sexual exploration and development (Arnett, 2004; Lefkowitz \& Gillen, 2006) and many researchers have explored the role of media in this process, finding that sexual images in mainstream media outlets as well as more sexually explicit materials are important sources of information for adolescents and young adults (e.g., Brown, 2006; Peter \& Valkenburg, 2007; Træen, Sørheim-Nilsen, \& Stigum, 2006; Ward, 2003). With the proliferation of available sexually explicit media in the last ten years, researchers are beginning to turn their attention to the ways in which contemporary youth are being impacted by sexually explicit media in particular (e.g., Carroll et al., 2008; Peter \& Valkenburg, 2006, 2009; Stulhofer, Busko \& Landripet, 2010).

Despite a long history of research on sexually explicit media, much of this research has become outdated as a result of significant technological shifts that have drastically changed the way people access sexually explicit materials (SEM), namely internet-based access has increased substantially in the last decade (Buzzell, 2005). Additionally, research on SEM has traditionally focused on potential links between SEM and sexual violence (e.g., Bensimon, 2007; Malamuth, Addison, \& Koss, 2000; Marshall, 1988) and its associations with sexual compulsions or addiction (e.g. Cooper, Delmonico, \& Burg, 2000; Delmonico, 1997) as opposed to its use among non-clinical, normative samples. While these are important areas of investigation, given that many teens and the majority of young adults report viewing sexually explicit media (e.g., Braun-Courville \& Rojas, 2009; Cameron et al., 2005), it is also important to examine potential associations between SEM use and more normative sexual and romantic relationship development during young adulthood. As such, the present study seeks to further our understanding of how levels of SEM use during adolescence and young adulthood are associated with certain sexual behaviors, sexual and relationship satisfaction, and sexual preferences reflective of those commonly presented in SEM.

\section{Definitions and Use of SEM}

For this study, sexually explicit material was broadly defined as media portraying images of exposed genitals and/or depictions of sexual behaviors that are intended to increase sexual arousal; this definition is commensurate with those used in previous research (e.g., Carroll et al., 2008; Malamuth \& Impett, 2001; Peter \& Valkenburg, 2007). Adolescents and young adults are privy to SEM through a variety of genres, including but not limited to magazines, books, videos, and the internet. In recent years, research has identified the internet as both the most popular and diverse medium for viewing sexually explicit materials (Buzzell, 2005; Fisher \& Barak, 2001; Peter \& Valkenburg, 2006), which has, in part, been influenced by the accessibility, affordability, and anonymity provided to its users (Cooper, 1998). Indeed, much of the recent research focusing on rates of SEM use and how associations between 
SEM use and sexual attitudes and behaviors among adolescent and young adult populations has focused exclusively on internet-based exposure (e.g., Braun-Courville \& Rojas, 2009; Peter \& Valkenburg, 2009).

Despite the current general preference among young adults for internet-based SEM, several studies have found that adolescents and young adults report using offline SEM (e.g., books, magazine, movies and phone sex hotlines) at similar rates to online SEM (Boies, 2002; Ybarra \& Mitchell, 2005). Furthermore, research has suggested that the use of one type of SEM is highly correlated with the use of other forms of SEM, such as reading sexually explicit magazines, viewing sexual explicit videos, and watching sexually explicit videos online (Peter \& Valkenburg, 2007). As such, accurate measurements of general SEM use (including both frequency and variability) should inquire about multiple types of SEM to adequately capture the full range of experiences young adults have with SEM. Consequently, the current study examined both the frequency of SEM use across multiple media types as well as viewing rates of individual SEM types in an attempt to obtain a more accurate understanding of overall SEM use among contemporary college students and its associations with sexual behavior, sexual and relationship satisfaction, and sexual preferences.

Rates of SEM use. Research has documented varying rates of SEM use from adolescence to adulthood, all of which consistently reveal a higher rate of use among males than females. For example, ever having intentionally used both online and offline SEM among a sample of 1,484 adolescents (10-18 years old) in the United States was documented at $25 \%$ for boys and $5 \%$ for girls (Ybarra \& Mitchell, 2005). A study of 433 older participants (12-22 years old, $\left.\mathrm{M}_{\mathrm{age}}=18\right)$ in the U.S. found that $85 \%$ of males and $50 \%$ of females reported having ever either intentionally or accidentally visited a sexually explicit website (Braun-Courville \& Rojas, 2009). Within a sample of 506 U.S. college students, $59 \%$ of men and 34\% reported ever having accessed SEM online for sexual entertainment purposes (Goodson, McCormick, \& Evans, 2001). Reported rates of having ever intentionally used SEM (including multiple types) among 813 U.S. college students included $86 \%$ of men and $31 \%$ of women (Carroll et al., 2008).

Overall, rates of SEM use have been examined and documented in a handful of studies that have yielded highly divergent results. These differences are attributable to the discrepancies in terminology and measurement of SEM itself and SEM use as well as related to demographic factors such as gender, age, and cultural context. As such, more information is needed regarding contemporary young adults' use of a variety of types of SEM. Additionally, because the majority of recent research assesses only online SEM use and many are conducted outside of the United States (see Carroll et al., 2008 for an exception), it is important to extend studies of general SEM use to young adults in the United States.

Gender and SEM use. Some research has explored how men and women may use SEM differently. Overwhelmingly this research indicates that men consume more SEM, both regarding time and frequency (Carroll et al., 2008; Hald, 2006). Additionally, men are generally exposed to SEM at a younger age than are women (Hald, 2006; Johansson \& Hammerén, 2007). Regarding the contexts within which men and women use SEM, research indicates that while men use SEM more often during solitary sexual activity, women have indicated a preference for relationally-based SEM, such as using it more frequently with a romantic partner or engaging in interactive sexual activity online (Ferree, 2003; Hald, 2006; Johansson \& Hammerén, 2007). Furthermore, men are more likely to seek out and experience sexual arousal in response to SEM, as well as to use SEM as masturbatory aids than women (Boies, 2002; Paul, 2009; Wasserman \& Richmond-Abbott, 2005).

These consistent differences in men and women's use of SEM have predominantly been explained through SEM's male-oriented content that promotes male sexual prowess and sexually objectifies women (Brosius et al., 1993; Jensen \& Dines, 1998). Indeed, both men and women are more likely to agree that SEM degrades women than men (Træen, Spitznogle, \& Beverfjord, 2004). Gender differences have also been explained by noting that young women tend to view SEM consumption as less socially acceptable than young men (Carroll et al., 2008). For example, Johansson and Hammerén (2007) found that men tend to describe SEM as more sexually exciting than women and were classified more often as "porno enthusiasts" while women were more often classified as "porno opponents." Overall, research has consistently revealed gender differences in SEM use and has identified several reasons for these gender differences. Nonetheless, systematic gender analyses regarding frequency, type, and context of SEM use have yet to be examined simultaneously and thus further examination of the role of gender in SEM use and its associations with sexual behaviors, satisfaction, and preferences is needed. 


\section{SEM Use and Sexual Behaviors, Satisfaction, and Preferences}

The central goals of the present study involve investigating potential associations between young adults' SEM use and their sexual behaviors, sexual and relationship satisfaction, and sexual preferences. Several theories provide a useful basis for understanding how SEM use might be associated with young adults' sexual development. First, cultivation theory posits that repeated exposure to commonly portrayed media messages fosters corresponding attitudes and beliefs in those who use it (Gerbner, Gross, Morgan, \& Signorielli, 1994). Thus, we would expect frequent consumers of SEM to cultivate sexual preferences, criteria for satisfaction, and possibly sexual behaviors, that are similar to those often portrayed in sexual explicit images, videos, or narratives. The Media Practice Model furthermore proposes that individuals are active in selecting and reacting to sexual media that speak to their emerging sense of self and identity as it pertains to their sexuality (Brown, 2000). As a result, those adolescents and young adults who seek out SEM and use it more frequently may indeed have distinct attitudes, preferences, and behaviors that could both lead towards and be intensified by their SEM use.

Gagnon and Simon's (2005) sexual script theory also provides a valuable theoretical foundation for the supposition that exposure to SEM may guide possible and acceptable sexual behaviors as well as criteria for sexual satisfaction towards those depicted in SEM. In theory, imagery presented in SEM may influence one's scripting of what constitutes "good" sex and expectations for one's own, and one's partner's, sexual roles and appearance. Indeed, research has identified associations between consumption of sexualized media and sexual attitudes and behaviors (e.g., Kim \& Ward, 2004; Zurbriggen \& Morgan, 2006) and it is reasonable to expect these associations could extend to SEM consumption (Stulhofer et al., 2010).

To understand the potential ways in which SEM use is associated with particular sexual behaviors and preferences, it is important to know how sexuality is portrayed in SEM. Content analyses of SEM have revealed common themes of male sexual prowess, female sexual availability, casual sexual encounters and exaggerated sexual pleasure (Brosius, Weaver, \& Staab, 1993; Jensen \& Dines, 1998). Explicit messages about optimal sexual behaviors are often also presented in advice columns embedded within mainstream media and SEM. For example, Krassas, Blauwkamp, and Wesselink (2003) identified ten themes presented to men regarding their sexuality in magazine articles. These included that the more (heterosexual) sex and sexual partners a man has the better, that kinky or unusual sex is better, and that threesomes between two women and a man are highly desirable.

In content analyses of women's and men's magazines promoting "great sex," Menard and Kleinplatz (2008) further noted that common messages revolved around sexual variety and experimentation, such as the use of sexual props, "kinky" activities such as mild bondage, role-play, and dirty talk, watching pornography together, and partaking in "rough," female-initiated sex. Another common theme (generally directed towards women) was "pre-sex preparation," which included personal appearance and grooming advice such as what clothes are "sexy" and appropriate pubic hair removal. Overall, content analyses suggest that in addition to highlighting male sexual prowess and female sexual subordination, sexually explicit media depicts sexual activities that are uncommon in their variety and sexual performances that are unrealistic in their intensity (e.g., Brosius et al., 1993; Jensen \& Dines, 1998).

Little research has specifically examined how SEM use is associated with sexual behaviors, satisfaction, and preferences. The majority of researchers exploring associations between SEM use and sexual behaviors focus on sexual violence (e.g., Malamuth et al., 2000), finding associations between SEM use and increased sexual perpetration and aggression, the trivialization of criminal behavior (e.g., rape), and increased risk for sexual deviancy (Kingston, Malamuth, Fedoroff \& Marshall, 2009; Manning, 2006). Several studies have explored associations between SEM use and sexual risk behaviors, finding that adolescents and young adults who use SEM tend to have more sexual partners, to have used alcohol or another substance at their last sexual encounter, to not have used contraception during sexual intercourse, and to have had an STD (Braun-Courville \& Rojas, 2009; Carroll et al., 2008; Haggstrom-Nordin, Hanson, \& Tyden, 2005; Wingood et al., 2001). SEM use and acceptance has also been associated with greater acceptance of casual sex among college men and women (Carroll et al., 2008).

In addition to its associations with sexual behaviors, SEM use has also been linked to sexual satisfaction and satisfaction with one's sexual partner in several studies. In a recent longitudinal study, Peter and Valkenburg (2009) found that more frequent exposure to internet-based SEM decreased both male and female Dutch adolescents' sexual satisfaction and that this effect was stronger for less sexually experienced teens. Experimental studies have 
also shown that men who were exposed to SEM found their partners less sexually attractive, rated themselves as less in love with their partners (Kenrick, Gutierres, \& Goldberg, 1989) and were less satisfied with their (female) partners' bodies (Weaver, Masland, \& Zillmann, 1984) than those who viewed neutral stimuli. Also, when SEM was viewed consistently over time, Zillmann and Bryant (1988) found that participants were less satisfied with their partners' physical appearance, affection, sexual curiosity, and sexual performance than those in a control group.

While no research has specifically examined associations between SEM use and sexual preferences, research has identified a number of sexual attitudes often associated with use of SEM. For example, Taylor (2006) found that reading both semi-explicit and explicit magazines was associated with more permissive attitudes towards premarital sexual activity and expectations of variety for both usual and unusual sexual behaviors among college men. SEM use has also been associated with lowered sexual anxiety and more positive sexual esteem (Morrison, Harriman, Morrison, Bearden, \& Ellis, 2004). Heavy SEM users themselves have also indicated self-perceived positive effects of SEM on their sex lives, including increased sexual knowledge and more positive attitudes towards sex (Hald \& Malamuth, 2008).

While past research has identified important associations between SEM use and sexual risk behaviors, more permissive sexual attitudes, and less sexual satisfaction, there are limitations and remaining gaps in this literature. In particular, many studies assessing these associations simply divide participants into SEM viewers and non-viewers (e.g., Braun-Courville \& Rojas, 2009) rather than examining viewing frequency levels. Additionally, most recent studies only measure online SEM use (e.g. Peter \& Valkenburg, 2009), without taking into account the use of other types of SEM. Additionally, no studies have actually assessed the number of different types of SEM participants have viewed and the potential role multi-type SEM use may have on young adults' sexual development. Furthermore, while studies have explored associations between SEM use and basic sexual attitudes towards recreational or casual sex, no research has examined whether SEM use is associated with preferences for the specific kinds of sexual behaviors represented in SEM.

\section{Current Study}

As a result of the gaps in the literature, the present study was designed to extend the research on young adults' contemporary experiences with SEM and outcomes of SEM use through an examination of SEM use, including frequency and number of SEM types viewed, and its associations with sexual behavior, sexual and relationship satisfaction, and sexual preferences. First, to gain a more comprehensive understanding of young adults' contemporary SEM use, rates and types of SEM used were assessed, along with contexts of SEM viewing and compulsive SEM use. Gender comparisons were conducted on each of these variables. Based on past research, it was expected that men would report more frequent use, greater variety in types used and more compulsive use (Carroll et al., 2008; Hald, 2006; Johansson \& Hammerén, 2007).

The main research questions concern potential associations between SEM viewing frequency, number of types of SEM viewed and participants' sexual behavior, sexual and relationship satisfaction, and sexual preferences. It was anticipated that SEM viewing frequency would be associated with more and earlier sexual experience (Carroll et al., 2008), less sexual and relationship satisfaction (Peter \& Valkenburg, 2009) and more varied or unusual sexual preferences (Taylor, 2006). Though no past research has examined the role of viewing multiple types of SEM, it was anticipated that it will have similar outcomes as SEM viewing frequency.

\section{Method}

\section{Participants}

Participants for this study included 782 college students from the Northwest region of the United States (326 men and 456 women); all participants identified as heterosexual (58 participants identifying with a sexual orientation other than heterosexual were excluded from analyses). Participants' ages ranged from 18 to $30(M=19.9)$. Participants' racial backgrounds included European-American/White $(n=640 ; 82 \%)$, Mexican-American/Latina $(n$ $=52 ; 7 \%)$, Asian-American/Pacific Islander $(n=25 ; 3 \%)$, Bi/Multi-racial $(n=24 ; 3 \%)$, Black/African-American $(n$ $=15 ; 2 \%)$, and other $(n=26 ; 3 \%)$. Participants' reported religious affiliations included Christian $(n=351 ; 45 \%)$, Catholic $(n=126 ; 16 \%)$, Agnostic $(n=102 ; 13 \%)$, Mormon/LDS $(n=57 ; 7 \%)$, Atheist $(n=54 ; 7 \%)$, and other $(n=$ $92 ; 12 \%)$. Participants average religiosity was $2.58(s d=1.31)$ on a 1 (Not at all) to 5 (Very religious) scale. Over 
$90 \%$ of participants' mothers and fathers had completed high school with $45 \%$ of mothers and $52 \%$ of fathers having obtained a college degree. Ten percent of mothers and $18 \%$ of fathers had completed a graduate degree. Just over half of participants were in a romantic relationship $(55.2 \%, n=432)$ while $44.8 \%$ reported that their dating status was single $(n=350)$.

\section{Procedure}

All participants were college students enrolled in a lower division psychology course at a public university in the Northwest United States and participated in the study to fulfill a course requirement. Students were recruited via an online educational experiment system where they were given information about the content of the questionnaire ("This study involves answering survey questions about your relationship experiences and satisfaction, your sexual experiences, and pornography usage") and elected to participate in the study. Upon signing up for the study, participants were given a URL for the study and completed the questionnaire via a secure, online survey website (http://www.psychsurveys.org). Participants were informed that all answers were confidential and that names would be removed from the data once credit allocation took place. The procedure, including consent, debriefing, and credit allocation, took place online in a location of the participants' choosing. After giving consent, participants completed a series of questions assessing demographics, sexual and romantic relationship experience, and experiences with sexually explicit material. Several other measures were used that were not assessed in the present study. The questionnaire took approximately 60 minutes to complete.

\section{Measures}

In addition to a demographic questionnaire, participants completed the following measures: experiences with sexual explicit material, sexual behaviors, sexual and relationship satisfaction, and sexual preferences.

Experiences with sexually explicit material. The present study aimed to assess self-selected and purposeful SEM use, which the Media Practice Model suggests is an important component of media influence (Brown, 2000). Because many adolescents report accidently or unintentionally viewing SEM (e.g. Cameron et al., 2005), participants were instructed to report on intentional SEM use. As such, participants were informed that: "Viewing Pornography" means that you are intentionally looking at (a) pictures with nude individuals; (b) movies with nude individuals; (c) pictures in which people are having sex; (d) movies in which people are having sex; (d) written or audio material that describe people having sex, or (e) real life nude individuals. Having sex implies vaginal, anal, or oral penetration. The term "pornography" was used in the questions because college students are likely familiar with this term and would therefore be more comfortable answering questions about "pornography" rather than "sexually explicit material", which is more general and potentially a more ambiguous term.

Frequency of SEM use was assessed with the question: "How often do you view pornography?" Response options included 0 (Never), 1 (Less than once a year), 2 (Once a year), 3 (Several times a year), 4 (Once a month), 5 (2-3 times a month), 6 (1-2 times a week), 7 (3-6 times a week), 8 (Once a day), 9 (More than once a day). This scale uses a similar breakdown in frequency of use as Carroll et al. (2008), but offers 10 options rather than six. Participants were also asked: "How old were you when you first viewed pornography?" To assess the different types of SEM used by young adults, participants indicated for each of 8 different types of SEM whether they had ever viewed it and if they have viewed it in the last 6 months. The types were based on those identified in past research (e.g., Boies, 2002; Peter \& Valkenburg, 2007; Ybarra \& Mitchell, 2005) and included sexually explicit rented videos, purchased videos, pay-per-view videos, magazines, books, telephone hotlines, online videos, and online photos. A sum of the number of SEM types ever viewed was calculated, with the resulting variable values ranging from 0 to 8 .

Contexts of SEM use were assessed through five questions. Participants were asked: "Do you view pornography with same-sex friends?"; "Do you view pornography with other-sex friends?"; "Do you view pornography with your current or most recent partner?"; Do you view pornography alone?"; and "Do you view pornography when masturbating?". Response options ranged from 1 (Never) to 5 (Always). 
Sexual behaviors. Three sexual behaviors were assessed: number of lifetime sexual intercourse partners (With how many people have you ever had sexual intercourse?), age at first sexual intercourse (How old were you the first time you had sexual intercourse?), and number of casual sex partners (Defining casual sex as sexual intercourse with someone with whom you are not in a monogamous or committed relationship, how many casual sex partners have you ever had?).

Sexual and relationship satisfaction. Two questions assessed sexual and relationship satisfaction: "How satisfied are you with your sexual relationships?" and "How satisfied are you with your romantic relationships?" Responses ranged from 1 (Not at all satisfied) to 5 (Very satisfied). The relationship satisfaction item is the highest loading item on Hendrick's (1988) seven-item Relationship Assessment Scale. Also, similar questions have been used in previous studies assessing sexual satisfaction (e.g., Liu, 2003; Peter \& Valkenberg, 2009).

Sexual preferences. Participants responded to a set of 14 items assessing sexual preferences (e.g. frequently initiate sex, role-play in sexual encounters, frequently does not wear underwear). This scale was designed for the present study as no previous measure of sexual preferences related to those typically depicted in SEM were available. Items were generated by the researcher based on their representation of messages found in previous content analyses of sexually explicit images and narratives (e.g., Jensen \& Dines, 1998; Menard \& Kleinplatz, 2008). Each sexual preference was listed after the following prompt: "For the following questions, please respond based on your own personal preferences. My ideal sexual partner would: ..." Response options ranged from 1 (Strongly disagree) to 5 (Strongly agree).

\section{Results}

\section{Factor Analysis of Sexual Preferences}

With the goal of reducing the 14 individual items in the sexual preference scale into meaningful categories, an exploratory factor analysis was conducted. An initial principal-axis factor analysis was conducted to determine whether assumptions necessary for EFA were met. The Kaiser-Meyer-Olkin measure of sampling adequacy for the initial EFA was .89, an acceptable value. Bartlett's test of sphericity was significant at the .001 level, indicating that the sample size was large enough to evaluate the factor structure. Since assumptions were met, an initial principalaxis factor extraction analysis using Varimax rotation was conducted. Examination of the scree plot and eigenvalues greater than one revealed three distinct factors among the data. No individual characteristics cross-loaded or had factor loadings less than .30. Factor loadings, means, and standard deviations for each item are presented in Table 1.

As a result of this data reduction process, three conceptually meaningful sexual preference categories emerged. The first category included six items and reflected sexual preferences related to "hot sex" (e.g., try different positions when having sex, make pleasure noises during sex). The percent variance explain by this factor was 18.01; Cronbach's alpha for this subscale was .82 , suggesting adequate reliability. The second category included five items and reflected sexual preferences related to "kinky sex" (e.g., participate in threesomes, enjoy using sex toys or props). The percent variance explain by this factor was 13.11; Cronbach's alpha for this subscale was .75, suggesting adequate reliability. The third category included four items and reflected sexual preferences related to "sexual appearance" (e.g., frequently not wear underwear, be clean and shaved). The percent variance explain by this factor was 11.83; Cronbach's alpha for this subscale was .70, suggesting adequate reliability.

\section{Rates of SEM Use by Gender}

Table 2 includes rates of SEM use and use of SEM by type for males and females. It also provides chi-square statistics indicating differences in use by gender. Additional analyses revealed that, on average, men reported viewing SEM about once a week $(M=5.27, S D=2.20)$ while women reported viewing it once a year $(M=1.72, S D$ $=1.89$ ); this was a significant difference, $t(683)=22.60, p<.001, d=1.73$. Regarding the frequency with which male and female participants used SEM, 58.1\% of men compared to $6.6 \%$ of women reported viewing SEM once a week or more. Male SEM users also reported first using SEM at a younger age $(M=12.39, S D=2.65)$ than female SEM users $(M=14.99, S D=3.40), t(550)=-10.09, p<.001, d=0.85$. Additionally, $98.7 \%$ of male SEM users and $76 \%$ of female SEM users reported first using SEM before the age of 18. Analyses also revealed that male participants were more likely have used all types of SEM than women except sexually explicit books. On average, men reported 
viewing $3.81(S D=2.40)$ different types of $S E M$, while women reported viewing $1.68(S D=2.05)$ different types; this was a significant difference, $t(780)=13.27, p<.001, d=0.95$.

Table 3 includes means, standard deviations, and t-tests examining the contexts within which male and female young adult SEM users viewed SEM. Because numerous t-tests were conducted, the alpha value was reduced to .01 to reduce the likelihood of a Type 1 error. Regarding contexts of use, overall, there was no difference between the amounts that male and female users reported viewing SEM with same-sex or other-sex friends (averages were low for both males and females). However, female users were more likely to report viewing SEM with a dating partner while male users were more likely to report viewing SEM alone, when not in a relationship, and when masturbating.

\section{Sexual Behaviors, Satisfaction, and Preferences}

To assess the relationship between SEM viewing frequency, SEM types viewed, and sexual behaviors, satisfaction, and preferences, bivariate correlations were first computed separately for men and women. Results are summarized in Table 4. Because numerous correlations were conducted, the alpha value was reduced to .01 to reduce the likelihood of a Type 1 e rror. For both genders, SEM viewing frequency was correlated with two of the sexual behavior variables. Participants who reported more frequent SEM also reported more casual sex partners and a younger age of first sexual intercourse. For females only, SEM viewing frequency was associated with a lower age at first intercourse. For males, SEM viewing frequency was also negatively correlated with sexual and relationship satisfaction. For women, SEM viewing frequency was not correlated with sexual satisfaction and was only marginally negatively correlated with relationship satisfaction. SEM viewing frequency was also positively correlated with all three sexual preferences for men and for all but sexual appearance for women.

Bivariate correlations between the number of SEM types viewed and sexual behaviors, satisfaction, and preferences were also computed (see Table 4). For both men and women, all three sexual behaviors were again associated with SEM types viewed. As before, participants who reported having viewed more SEM types also reported more sexual intercourse partners, more casual sex partners, and a younger age of first sexual intercourse. Neither sexual or relationship satisfaction was correlated with SEM types viewed for men or women. The number of SEM types viewed was positively correlated with all three sexual preferences for men and was significantly positively correlated with hot sex and kinky sex for women (appearance was marginally significantly correlated with SEM type). SEM viewing frequency and SEM types viewed were also positively correlated for men $(r(282)=0.178, p$ $=.003)$ and women $(r(454)=0.337, p<.001)$.

To examine further the relative importance of SEM viewing frequency and SEM types viewed in predicting sexual behaviors, satisfaction and preferences, a series of eight hierarchical regression analyses were conducted. In each analysis, a different sexual behavior, satisfaction or preference variable was regressed on the same set of predictors. In the first block of each regression, we included gender, religiosity, dating status and SEM viewing frequency. In the second block, SEM types viewed were added. Results are reported in Tables 5 and 6.

Sexual behavior. When gender, religiosity, and dating status were controlled, SEM viewing frequency was a reliable predictor of all three sexual behaviors (See Table 5). In all cases, SEM viewing frequency was associated more sexual activity (e.g., more sexual intercourse and casual sex partners) and a lower age at first sexual intercourse. When the SEM types viewed variable was added to the model, it too was a reliable predictor of all three sexual behaviors. Additionally, SEM viewing frequency remained significant even after adding in the SEM types variable, indicating that both variables individually and significantly predicted all three sexual behaviors.

Sexual and relationship satisfaction. When age, religiosity, and dating status were controlled, SEM viewing frequency was a reliable predictor of relationship satisfaction and sexual satisfaction (See Table 5). In both cases, as SEM viewing frequency increased, satisfaction diminished. When the SEM types variable was added to the model, it was not a reliable predictor of either satisfaction variables; however, SEM viewing frequency remained significant.

Sexual preferences. The main results were consistent across all three sexual preferences (See Table 6). When age, religiosity, and dating status were controlled, SEM viewing frequency was a reliable predictor of all three sexual preferences. In each case, SEM viewing frequency was associated a stronger endorsement of each set of preferences. When the SEM types viewed variable was added to the model, it too was a reliable predictor of all three sexual 
preferences. For all three sexual preferences, SEM viewing frequency remained significant even after adding in the SEM types variable, indicating that no mediation occurred.

\section{Discussion}

The purpose of this study was to ascertain frequencies, types, and contexts of general SEM use among young adult college students as well as examine associations between SEM use and sexual behaviors, sexual and relationship satisfaction, and sexual preferences. Finding indicated that the majority of young men and half of young women have used SEM with variability in frequency, type, and context by gender. Examining both how often SEM was used and how many types of SEM were used, the present study also suggested that these two variables were associated in interesting ways with aspects of participants' sexual behaviors, satisfaction, and preferences, lending support to the hypothesis that SEM use plays a role in the cultivation of sexual scripts during young adults' sexual development.

In the present study, $92 \%$ of young men and $50 \%$ of young women reported having ever used a variety of types of SEM. These frequencies were on the high end of those presented in other recent studies with young adults in the U.S., which ranged from 56-86\% of young men and 31-50\% of young women (Braun-Courville \& Rojas, 2009; Carroll et al., 2008; Goodson, McCormick, \& Evans, 2001). This is reasonable considering multiple types of SEM were assessed, but could also indicate that rates have risen slightly since previous research was conducted. An individual assessment of SEM types indicated that online photos, online videos, and magazines are the most frequently used types of SEM among both young men and women. Results also supported previous research that has found significant gender differences in viewing frequency and context (Carroll et al., 2008; Hald, 2006; Johansson \& Hammerén, 2007). The young men in the present study surpassed women in almost every capacity of SEM use, including higher current and past frequency of viewing, and an earlier age at first SEM use. Measuring a unique dimension of SEM use, this study also determined that young men make greater use of 7 out of 8 types of SEM and use more types of SEM than young women overall. Gender differences in contexts of use also supported past research that has indicated women prefer relationally-based SEM while men use SEM more frequently during solitary sexual activity (Ferree, 2003; Hald, 2006; Johansson \& Hammerén, 2007). Though these findings cannot speak to the reasons behind these gender differences, it is very possible that the male-oriented nature of SEM and ongoing gender differences in social desirability of SEM use could contribute these results.

Regarding associations between SEM use and sexual behavior, both SEM viewing frequency and the number of SEM types viewed uniquely predicted all three sexual behavior variables when controlling for gender, religiosity, dating status. These results suggest that both the frequency of SEM viewing and having a diverse SEM media diet are uniquely and significantly associated with sexual behavior. This is an important finding both because it supports and extends past research indicating that SEM use is associated with more sexual partners (e.g., Braun-Courville \& Rojas, 2009; Carroll et al., 2008) and because the number of SEM types viewed has not previously been assessed and therefore was not a known contributor to sexual behaviors. There are several possible explanations for these associations. First, more sexual experience may provide opportunities for and greater comfort with engaging in more frequent SEM use out seeking out more types of SEM. Conversely, it is possible that individuals may engage in more frequent and varied SEM use, and as a result, seek out more sexual experience. The unique contributions of both frequency of SEM viewing and SEM types might be explained by the SEM viewing frequency variable assessing "current" viewing habits, while the SEM types variable was assessing the lifetime number of SEM types viewed. As such, these contributions may relate to the simultaneous role of both "short-term" and "long-term" SEM use in sexual behavior.

Regression results further revealed that SEM viewing frequency played a unique role in predicting sexual and relationship satisfaction for college students. Specifically, higher viewing frequency was associated with less sexual and relationship satisfaction when controlling for gender, religiosity, dating status and the number of SEM types viewed. The number of SEM types viewed was not associated with either satisfaction variable. One previous study established a negative association between online SEM use and sexual satisfaction among Dutch adolescents (Peter \& Valkenburg, 2009); these results extend the relationship to general SEM use and relationship satisfaction. It is important to recognize that SEM viewing frequency either could contribute to lower sexual and relationship satisfaction or that a non-satisfying sex-life or relationship might contribute to more frequent SEM viewing. What is also noteworthy is that frequency of SEM use was predictive even when controlling for dating status, which understandably was highly predictive of sexual and relationship satisfaction. 
Lastly, regression analyses revealed that both SEM viewing frequency and the number of SEM types viewed uniquely predicted all three sexual preference variables. These robust relationships (particularly with the "kinky sex" subscale) indicate that heavy consumers of SEM hold similar sexual preferences to those frequently portrayed in SEM (e.g., Jensen \& Dines, 1998; Krasses et al., 2003; Menard \& Kleinplatz, 2008). However, because these data are cross-sectional, these results suggest only an association between these variables; it is necessary to understand that exposure to SEM may shape sexual preferences and that young adults often selectively seek sexual media whose messages correspond with pre-existing preferences. Interestingly, though, the average age of first SEM use preceded the average age of first sexual intercourse by two to four years, suggesting that the majority of participants likely engaged with SEM prior to developing preferences based on their own sexual experiences.

In sum, the findings from this study reveal that multiple dimensions of SEM use, including frequency of use and number of types used, share significant associations with young adults' sexual behaviors, sexual and relationship satisfaction and sexual preferences. In addition, because a substantial proportion of the young adults in this study reported using SEM, the potential implications are especially noteworthy, particularly for young men. It appears as though SEM use is associated with a specific sexual preferences in addition to being associated with earlier and great sexual experiences as well as lower sexual and relationship satisfaction. This combination reveals that despite having a well-defined set of preferences and experiences, individuals frequently using SEM are nonetheless less satisfied with these experiences. This difference could reflect a disconnect between their preferences and their actual sexual and relationship experiences, suggesting that SEM viewing may indeed set up young adults to expect unrealistic sexual encounters. It would be beneficial for future research to further examine how SEM viewing during this time of substantive sexual development may cultivate unrealistic attitudes and preferences that ultimately lead adolescents and young adults to be disappointed in their own more normative sexual experiences. Additionally, it would be beneficial to further explore whether or not these preferences precede or follow SEM use and better understand the role of the use of a diverse array of SEM types in sexual attitudes and behaviors.

Despite offering new and interesting findings, this study has several limitations that future research could address. First, because participants self-selected into the study, it is possible that a non-representative sample of college students was obtained. Furthermore, it is possible that social-desirability influenced participants' responses and drove some of the associations between SEM use and sexual behaviors and preferences. In other words, participants who were willing to report frequent SEM use may also be more willing to report interests in kinky sex or having had a higher number of intercourse partners. Next, because the present study necessarily used an exploratory assessment of number of SEM types viewed and sexual preferences and used researcher-generated measures of sexual behavior and satisfaction, further verification and assessment of these constructs is needed. Recognizing the potentially unique role of viewing multiple types of SEM regarding young adults' sexual behaviors, future research could extend this line of inquiry. Additionally, studies that longitudinally or experimentally examine associations between SEM use and sexual preferences would help clarify the direction of this relationship. Extending research on SEM use and sexual behaviors, sexual preferences, and sexual and relationship satisfaction to other samples of U.S. college students and to non-college young adult populations as well as include analyses of sexual-minority individuals would also help generalize these results beyond the limited sample in the present study.

Overall, recognizing the prevalence of SEM use among young adult college students (and the likelihood that SEM use began in adolescence) is important for parents and educators alike as exposure to these media provide adolescents and young adults with information about sexuality and present sexual encounters that are unrealistic or uncommon as desirable. Indeed, more frequent viewing and exposure to multiple types of SEM was associated with holding sexual preferences reminiscent of those frequently presented in SEM. Additionally, knowing that young adult college students who frequently use SEM and have viewed multiple types of SEM are likely to be less satisfied with their sexual and romantic relationships supports the need to discuss SEM use in programming aimed at increasing sexual and relationship satisfaction among this population. Despite the proliferation of research on sexually explicit media, this study identifies the need for continued empirical attention regarding the ways in with SEM use impacts adolescent and young adults' normative sexual development. 


\section{References}

Arnett, J. J. (2004). Emerging adulthood: The winding road from the late teens through the twenties. New York: Oxford University Press.

Bensimon, P. (2007). The role of pornography in sexual offending. Sexual Addiction \& Compulsivity, 14, 95-117.

Boies, S. C. (2002). University students' uses of and recreations to online sexual information and entertainment: Links to online and offline sexual behavior. Canadian Journal of Human Sexuality, 11, 77-89.

Braun-Courville, D. K., \& Rojas, M. (2009). Exposure to sexually explicit web sites and adolescent sexual attitudes and behaviors. Journal of Adolescent Health, 45, 156-162.

Brosius, H., Weaver, J. B., \& Staab, J. F. (1993). Exploring the social and sexual "reality" of contemporary pornography. Journal of Sex Research, 30, 161-170.

Brown, J. D. (2000). Adolescents' sexual media diets. Journal of Adolescent Health, 27, 35-40.

Brown, J. D. (2006). Emerging Adults in a Media-Saturated World. In J. J. Arnett, J. L. Tanner (Eds.), Emerging adults in America: Coming of age in the 21st Century (pp. 279-299). Washington DC: American Psychological Association.

Buzzell, T. (2005). The effects of sophistication, access, and monitoring on use of pornography in three technological contexts. Deviant Behavior, 26, 109-132.

Cameron, K. A., Salazar, L. F., Bernhardt, J. M., Burgess-Whitman, N., Wingood, G. M., \& DiClemente, R. J. (2005). Adolescents' experience with sex on the web: Results from online focus groups. Journal of Adolescence, 28, 535-540.

Carroll, J. S., Padilla-Walker, L. M., Nelson, L. J., Olson, C. D., McNamara Barry, C., \& Madsen, S. D. (2008). Generation XXX: Pornography acceptance and use among emerging adults. Journal of Adolescent Research, 23, 6-30.

Cooper, A. (1998). Sexuality and the internet: Surfing into the new millennium. CyberPsychology \& Behavior, 1 , 187-193.

Cooper, A., Delmonico, D. L., \& Burg, R. (2000). Cybersex users, abusers, and compulsives: New findings and implications. Sexual Addiction \& Compulsivity, 7, 5-29.

Cooper, A., Galbreath, N., \& Becker, M. A. (2004). Sex on the internet: Furthering our understanding of men with online sexual problems. Psychology of Addictive Behaviors, 18, 223-230.

Delmonico, D. L. (1997). Cybersex: High tech sex addiction. Sexual Addiction \& Compulsivity, 4 (2), 159 -167.

Ferree, M. C. (2003). Women and the web: Cybersex activity and implications. Sexual and Relationship Therapy, 18, 385-393.

Fisher, W. A., \& Barak, A. (2001). Internet pornography: A social psychological perspective on internet sexuality. Journal of Sex Research, 38, 312-323.

Gagnon, J. H., \& Simon, W. (2005). Sexual conduct: The social sources of human sexuality. New Brunswick, NJ: Aldine Transaction.

Gerbner, G., Gross, L., Morgan, M., \& Signorielli, N. (1994). Growing up with television: The cultivation perspective. In J. Bryant, D. Zillmann (Eds.), Media effects: Advances in theory and research (pp. 17-41). Hillsdale, NJ: Lawrence Erlbaum Associates

Goodson, P., McCormick, D., \& Evans, A. (2001). Searching for sexually explicit material on the Internet: An exploratory study of college students' behavior and attitudes. Archives of Sexual Behavior, 30, 101-117.

Haggstrom-Nordin, E., Hanson, U., \& Tyden, T. (2005). Associations between pornography consumption and sexual practices among adolescents in Sweden. International Journal of STD \& AIDS, 16, 102-107.

Hald, G. M. (2006). Gender differences in pornography consumption among young heterosexual Danish adults. Archives of Sexual Behavior, 35, 577-585.

Hald, G. M., \& Malamuth, N. M. (2008). Self-perceived effects of pornography consumption. Archives of Sexual Behavior, 37, 614-625.

Hendrick, S. S. (1988). A generic measure of relationship satisfaction. Journal of Marriage and Family, 50, 93-98.

Jensen, R., \& Dines, G. (1998). The content of mass-marketed pornography. In G. Dines, R. Jensen, \& A. Russo (Eds.), Pornography: The production and consumption of inequality (pp. 65-100). New York: Routledge.

Johansson, T., \& Hammerén, N. (2007). Hegemonic masculinity and pornography: Young people's attitudes toward and relations to pornography. The Journal of Men's Studies, 15, 57-70.

Kenrick, D., Gutierres, S., \& Goldberg, L. (1989). Influence of popular erotica on judgments of strangers and mates. Journal of Experimental Social Psychology, 25, 159-167.

Kim, J. L., \& Ward, L. M. (2004). Pleasure reading: Associations between young women's sexual attitudes and their reading of contemporary women's magazines. Psychology of Women Quarterly, 28, 48-58. 
Kingston, D. A., Malamuth, N. M., Fedoroff, P., \& Marshall, W. L. (2009). The importance of individual differences in pornography use: Theoretical perspectives and implications for treating sexual offenders. Journal of Sex Research, 46, 216-232.

Krassas, N. R., Blauwkamp, J. M., \& Wesselink, P. (2003). "Master your Johnson”: Sexual rhetoric in Maxim and Stuff magazines. Sexuality \& Culture, 7, 98-119.

Lefkowitz, E. S., \& Gillen, M. M. (2006). "Sex is just a normal part of life": Sexuality in emerging adulthood. In J. J. Arnett, J. L. Tanner (Eds.), Emerging adults in America: Coming of age in the 21st century (pp. 235256). Washington DC: American Psychological Association.

Liu, C. (2003). Does quality of marital sex decline with duration? Archives of Sexual Behavior, 32, 55-60.

Malamuth, N. M., Addison, T., \& Koss, M. (2000). Pornography and sexual aggression: Are there reliable effects and can we understand them? Annual Review of Sex Research, 11, 26-91.

Malamuth, N. M., \& Impett, E. A. (2001). Research on sex and media: what do we know on the effects on children and adolescents? In D. G. Singer, \& J. L. Singer (Eds.), Handbook of children and media (pp. 269-287) Thousand Oaks: Sage.

Manning, J. C. (2006). The impact of internet pornography on marriage and the family: A review of the research. Sexual Addiction \& Compulsivity, 13, 131-165.

Marshall, W. L. (1988). The use of sexually explicit stimuli by rapists, child molesters, and nonoffenders. Journal of Sex Research, 25, 267-288.

Menard, A. D., \& Kleinplatz, P. J. (2008). Twenty-one moves guaranteed to make his thighs go up in flames: Depictions of "great sex" in popular magazines. Sexuality \& Culture, 12, 1-20.

Morrison, T. G., Harriman, R., Morrison, M. A., Bearden, A., \& Ellis, S. R. (2004). Correlates of exposure to sexually explicit material among Canadian post-secondary students. The Canadian Journal of Human Sexuality, 13, 143-156.

Paul, B. (2009). Predicting internet pornography use and arousal: The role of individual difference variables. Journal of Sex Research, 46, 344-357.

Peter, J., \& Valkenburg, P. M. (2006). Adolescents' exposure to sexually explicit online material and recreational attitudes toward sex. Journal of Communication, 56, 639-660.

Peter, J., \& Valkenburg, P. M. (2007). Adolescents' exposure to a sexualized media environment and their notions of women as sex objects. Sex Roles, 56, 381-395.

Peter, J., \& Valkenburg, P. M. (2009). Adolescents' exposure to sexually explicit internet material and sexual satisfaction: A longitudinal study. Human Communication Research, 35, 171-194.

Stulhofer, A., Busko, V., \& Landripet, I. (2010). Pornography, sexual socialization, and satisfaction among young men. Archives of Sexual Behavior, 39, 168-178.

Taylor, L. D. (2006). College men, their magazines, and sex. Sex Roles, 55, 693-702.

Træen, B., Sørheim-Nilsen, T., \& Stigum, H. (2006). Use of pornography in traditional media and on the internet in Norway. Journal of Sex Research, 43, 245-254.

Træen, B., Spitznogle, K., \& Beverfjord, A. (2004). Attitudes and use of pornography in the Norwegian population 2002. Journal of Sex Research, 41, 191-200.

Ward, L. (2003). Understanding the role of entertainment media in the sexual socialization of American youth: A review of empirical research. Developmental Review, 23, 347-388.

Wasserman, I. M. \& Richmond-Abbott, M. (2005). Gender and the Internet: Causes of variation in access, level, and scope of use. Social Science Quarterly, 86, 252-270.

Weaver, J., Masland, J., \& Zillmann, D. (1984). Effect of erotica on young men's aesthetic perception of their female sexual partners. Perceptual and Motor Skills, 58, 929-930.

Wingood G. M., DiClemente R. J., Harrington K., Davies, S., Hook, E. W., \& Oh, M. K. (2001). Exposure to Xrated movies and adolescents' sexual and contraceptive-related attitudes and behaviors. Pediatrics, 107, $116-119$.

Ybarra, M., \& Mitchell, K. J. (2005). Exposure to internet pornography among children and adolescents: A national survey. CyberPsychology \& Behavior, 8, 473-486.

Zillmann, D., \& Bryant, J. (1988). Pornography's impact on sexual satisfaction. Journal of Applied Social Psychology, 18, 438-453.

Zurbriggen, E., \& Morgan, E. M. (2006). Who Wants to Marry a Millionaire? Reality Dating Television Programs, Attitudes Toward Sex, and Sexual Behaviors. Sex Roles, 54, 1-17. 
Table 1

Summary of Items and Standardized Factor Loadings for the Sexual Preferences Scale.

\begin{tabular}{|c|c|c|c|c|c|}
\hline \multirow[b]{2}{*}{ Item } & \multicolumn{3}{|c|}{ Factor Loading } & \multicolumn{2}{|c|}{ Items } \\
\hline & 1 & 2 & 3 & Mean & $\mathrm{SD}$ \\
\hline \multicolumn{6}{|l|}{ Hot Sex Subscale } \\
\hline Frequently initiates sex & .665 & .173 & .276 & 3.83 & 0.89 \\
\hline Have a very high sex drive & .657 & .176 & .292 & 3.77 & 0.93 \\
\hline Try different positions during sex & .635 & .160 & .173 & 4.24 & 0.79 \\
\hline Make pleasure noises during sex & .554 & .206 & .285 & 3.94 & 0.92 \\
\hline Talk dirty during sex & .527 & .210 & .157 & 3.34 & 1.10 \\
\hline Make me orgasm every time we have & .486 & .071 & .273 & 3.97 & 0.99 \\
\hline $\operatorname{sex}$ & & & & & \\
\hline \multicolumn{6}{|l|}{ Kinky Sex Subscale } \\
\hline Watch pornography with me & .169 & .707 & .160 & 2.11 & 1.19 \\
\hline Enjoy using sex toys or props & .219 & .606 & .050 & 2.78 & 1.15 \\
\hline Participate in threesomes & .088 & .529 & .262 & 1.87 & 1.14 \\
\hline $\begin{array}{l}\text { Playfully dominate me during sexual } \\
\text { encounters }\end{array}$ & .212 & .500 & -.115 & 3.58 & 1.09 \\
\hline Role play in sexual encounters & .297 & .490 & .225 & 3.00 & 1.07 \\
\hline \multicolumn{6}{|l|}{ Sexual Appearance Subscale } \\
\hline Dress in sexy lingerie/underwear & .111 & .278 & .756 & 3.21 & 1.23 \\
\hline Frequently dress sexy & .230 & .246 & .532 & 3.42 & 1.03 \\
\hline Frequently not wear underwear & .154 & .208 & .451 & 2.57 & 1.13 \\
\hline Be clean and shaved & .199 & .010 & .349 & 4.13 & 0.88 \\
\hline
\end{tabular}

Note. Response scale for items ranged from $1=$ Strongly disagree to $5=$ Strongly agree. 
Table 2

Tests of Gender Differences in Rates and Types of SEM use.

\begin{tabular}{lcccc}
\hline Variable & Men & Women & Chi & Cramer's Phi \\
\hline Ever viewed SEM & $299(91.7 \%)$ & $228(50.0 \%)$ & $150.55^{* * *}$ & .439 \\
Viewed in past 6 months & $257(78.8 \%)$ & $141(30.9 \%)$ & $84.98 * * *$ & .379 \\
SEM Types & & & & \\
Online pictures & $262(80.4 \%)$ & $152(33.3 \%)$ & $168.80 * * *$ & .465 \\
Online videos & $234(71.8 \%)$ & $106(23.2 \%)$ & $97.60 * * *$ & .406 \\
Magazines & $232(71.2 \%)$ & $152(33.3 \%)$ & $108.87 * * *$ & .373 \\
Purchased videos & $85(26.1 \%)$ & $48(10.5 \%)$ & $32.55 * * *$ & .204 \\
Pay-per-view videos & $82(25.2 \%)$ & $34(7.5 \%)$ & $47.13 * * *$ & .245 \\
Books & $82(25.2 \%)$ & $80(17.5 \%)$ & 6.70 & .093 \\
Telephone hotlines & $26(8.0 \%)$ & $9(2.0 \%)$ & $16.02 * * *$ & .143 \\
Other & $47(14.4 \%)$ & $26(5.7 \%)$ & $17.06 * * *$ & .148 \\
\hline
\end{tabular}

Note. $\operatorname{Men}(N=326)$; Women $(N=456)$.

$* * * p<.001$ 


\section{Table 3}

Tests of Gender Differences in Contexts of SEM use.

\begin{tabular}{|c|c|c|c|c|c|c|}
\hline \multirow[t]{2}{*}{ Variable } & \multicolumn{2}{|c|}{ Men } & \multicolumn{2}{|c|}{ Women } & \multirow[t]{2}{*}{$t$} & \multirow[t]{2}{*}{ Cohen's $d$} \\
\hline & $M$ & sd & $M$ & $s d$ & & \\
\hline \multicolumn{7}{|l|}{ Contexts } \\
\hline View with same-sex friends & 1.56 & 0.77 & 1.55 & 0.96 & 0.15 & 0.011 \\
\hline View with other-sex friends & 1.63 & 0.91 & 1.65 & 1.03 & -0.25 & -0.021 \\
\hline View with dating partner & 1.49 & 0.89 & 1.86 & 1.18 & $-4.23 * * *$ & -0.354 \\
\hline View alone & 4.12 & 1.02 & 2.62 & 1.49 & $14.14 * * *$ & 1.174 \\
\hline When not in a relationship & 3.62 & 1.21 & 2.16 & 1.29 & $13.84 * * *$ & 1.167 \\
\hline With masturbation & 3.55 & 1.08 & 1.89 & 1.17 & $17.52 * * *$ & 1.474 \\
\hline
\end{tabular}

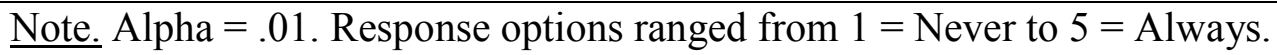

$* * * p<.001$ 
Table 4

Correlations Between SEM Viewing Frequency, Types Viewed, and Sexual Behaviors, Satisfaction, and Preferences Separately by Gender.

\begin{tabular}{|c|c|c|c|c|}
\hline \multirow[t]{3}{*}{ Variable } & \multicolumn{2}{|c|}{ Men } & \multicolumn{2}{|c|}{ Women } \\
\hline & SEM Viewing & SEM Types & SEM Viewing & SEM Types \\
\hline & Frequency & Viewed & Frequency & Viewed \\
\hline \multicolumn{5}{|l|}{ Sexual Behaviors } \\
\hline Age at first sex & -.155 & -.156 & $-.203 * *$ & -.155 \\
\hline Intercourse partners & $.196 * * *$ & $.290 * * *$ & $.375 * * *$ & $.385 * * *$ \\
\hline Casual sex partners & $.203 * * *$ & $.297 * * *$ & $.324 * * *$ & $.356 * * *$ \\
\hline \multicolumn{5}{|l|}{ Satisfaction } \\
\hline Sexual satisfaction & $-.158 * *$ & -.051 & -.035 & .068 \\
\hline Relationship satisfaction & $-.225 * * *$ & -.027 & $-.089^{\dagger}$ & .021 \\
\hline \multicolumn{5}{|l|}{ Sexual Preferences } \\
\hline Hot sex & $.282 * * *$ & $.225 * * *$ & $.307 * * *$ & $.265^{* * *}$ \\
\hline Kinky sex & $.314^{* * *}$ & $.297 * * *$ & $.522 * * *$ & $.411 * * *$ \\
\hline Sexual appearance & $.260 * * *$ & $.248 * * *$ & .147 & .070 \\
\hline
\end{tabular}

Note. Alpha $=.01 .{ }^{* * p<.01, * * * p<.001}$ 
Table 5

Hierarchical Regressions Predicting Sexual Behaviors and Satisfaction from Gender, Religiosity, Dating Status, SEM Viewing

Frequency, and SEM Types Viewed.

\begin{tabular}{|c|c|c|c|c|c|c|c|c|c|c|}
\hline \multirow[b]{2}{*}{ Predictor } & \multicolumn{2}{|c|}{$\begin{array}{l}\text { Age at first } \\
\text { intercourse }\end{array}$} & \multicolumn{2}{|c|}{ Sexual partners } & \multicolumn{2}{|c|}{$\begin{array}{c}\text { Casual sexual } \\
\text { partners }\end{array}$} & \multicolumn{2}{|c|}{ Sexual satisfaction } & \multicolumn{2}{|c|}{$\begin{array}{l}\text { Relationship } \\
\text { satisfaction }\end{array}$} \\
\hline & Step 1 & Step 2 & Step 1 & Step 2 & Step 1 & Step 2 & Step 1 & Step 2 & Step 1 & Step 2 \\
\hline \multicolumn{11}{|l|}{ Control variables } \\
\hline Gender & $-.19 * * *$ & $-.21 * * *$ & .06 & $.12 * *$ & .02 & .07 & $-.09 *$ & $-.09 *$ & $-.12 * *$ & $-.13 * *$ \\
\hline Religiosity & $.15^{* *}$ & $.16^{* *}$ & $-.17 * * *$ & $-.16 * * *$ & $-.12 * *$ & $-.11 * *$ & .01 & .01 & .02 & .02 \\
\hline Dating status & .03 & .04 & $.19 * * *$ & $.15^{* * *}$ & .04 & .01 & $.45 * * *$ & $.45 * * *$ & $.58^{* * *}$ & $.59 * * *$ \\
\hline SEM frequency & $-.14 * * *$ & $-.14 * *$ & $.26 * * *$ & $.15^{* *}$ & $.24 * * *$ & $.12 * *$ & $-.14 * *$ & $-.14 * *$ & $-.19 * * *$ & $-.18 * * *$ \\
\hline SEM types & & $-.13 * *$ & & $.28 * * *$ & & $.30 * * *$ & & .003 & & -.01 \\
\hline$\Delta R^{2}$ & & $.012 * *$ & & $.054 * * *$ & & $.062 * * *$ & & .000 & & .000 \\
\hline Total $R^{2}$ & $.064 * * *$ & $.076 * * *$ & $.132 * * *$ & $.186^{* * *}$ & $.082 * * *$ & $.144 * * *$ & $.215^{* * *}$ & $.215 * * *$ & $.357 * * *$ & $.357 * * *$ \\
\hline
\end{tabular}

Note. Control variables (gender, religiosity, and dating status) and SEM frequency were entered in the first block; SEM types was

added in the second block. Standardized partial regression coefficients ( $\beta$ 's) are reported. Only participants who reported having had sexual intercourse were included in "Age at first intercourse" regression $(N=648)$.

$* p<.05, * * p<.01, * * * p<.001$ 
Table 6

Hierarchical Regressions Predicting Sexual Preferences from Gender, Religiosity, Dating

Status, SEM Viewing Frequency, and SEM Types Viewed.

\begin{tabular}{|c|c|c|c|c|c|c|}
\hline \multirow[b]{2}{*}{ Predictor } & \multicolumn{2}{|c|}{$\begin{array}{l}\text { Hot sex } \\
(N=310)\end{array}$} & \multicolumn{2}{|c|}{$\begin{array}{l}\text { Kinky Sex } \\
(N=316)\end{array}$} & \multicolumn{2}{|c|}{$\begin{array}{c}\text { Sexual Appearance } \\
\qquad(N=317)\end{array}$} \\
\hline & Step 1 & Step 2 & Step 1 & Step 2 & Step 1 & Step 2 \\
\hline \multicolumn{7}{|l|}{ Control variables } \\
\hline Gender & $-.10 *$ & -.07 & $.09 * *$ & $.14 * * *$ & $-.39 * * *$ & $-.37 * * *$ \\
\hline Religiosity & -.07 & -.06 & $-.08 *$ & $-.07 *$ & -.05 & -.04 \\
\hline Dating status & $.16^{* * *}$ & $.14 * *$ & $.07 *$ & .04 & -.01 & -.01 \\
\hline SEM frequency & $.32 * * *$ & $.26 * * *$ & $.47 * * *$ & $.36 * * *$ & $.19 * * *$ & $.16^{* * *}$ \\
\hline SEM types & & $.14 * * *$ & & $.25 * * *$ & & $.09 *$ \\
\hline$\Delta R^{2}$ & & $.014 * * *$ & & $.042 * * *$ & & $.005 *$ \\
\hline Total $R^{2}$ & $.169 * * *$ & $.184 * * *$ & $.196 * * *$ & $.238 * * *$ & $.287 * * *$ & $.292 * * *$ \\
\hline
\end{tabular}

Note. Control variables (gender, religiosity, and dating status) and SEM frequency were entered in the first block; SEM types was added in the second block. Standardized partial regression coefficients $(\beta$ 's) are reported.

$* p<.05, * * p<.01, * * * p<.001$ 